\title{
La asistencia a colombianos solicitados en extradición区
}

\author{
The assistance to Colombians with order of extradition
}

Assistência a colombianos em extradição

Recibido el 8 de septiembre de 2016. Aceptado el 28 de marzo de 2017

Julio César Ramírez Montañez*

Colombia

\section{Resumen}

Objetivos: describir el trámite de la extradición de colombianos solicitados por Cortes Internacionales de Justicia, a partir de la experiencia de la Fundación por la Defensa de los Colombianos Pedidos en Extradición (DECOPEX); esto, con el fin de concretar una fuente de consulta sobre la extradición, en las tres últimas décadas en Colombia. Metodología: estudio descriptivo y documental que se desarrolló en dos fases: primero, se realizó la descripción del estudio con insumos que generó la entrevista a 650 internos del Pabellón 7 de la Penitenciaría de Máxima Seguridad

Para citar este artículo: Ramírez Montañez, Julio César (junio, 2017). La Asistencia a colombianos solicitados en extradición. Ánfora, 24(42), 117 - 137. Universidad Autónoma de Manizales. ISSN 0121-6538. de Cómbita; tales entrevistas se lograron en las visitas de los sábados entre 2007 y 2011. En la segunda fase, de carácter documental, se recopiló material escrito sobre los aspectos legales y de gestión en la Fundación DECOPEX y en una revisión bibliográfica. Resultados: entre 2000 y 2011 fueron extraditados 1221; el 2008 fue el de mayor número de extradiciones: 207. Los países requirentes con mayor número de solicitudes

\footnotetext{
* Magíster. Profesional en Relaciones Internacionales. Docente e investigador de la Universidad Pontificia Bolivariana, Seccional Bucaramanga. Correo electrónico: julio.ramirez@upb.edu.co
} 
fueron Estados Unidos, España y Perú. Los principales delitos son: narcotráfico, 75\%; delitos relacionados con el narcotráfico con 11\%; lavado de activos 10\%; homicidio 2 $\%$ y tráfico de migrantes 1\%. Conclusiones: en Colombia se aplica la extradición desde hace tres décadas, como mecanismo que facilita la colaboración judicial entre países. Es un trámite que dura entre 12 a 18 meses y está reglamentado en la Constitución Política de Colombia.

Palabras Claves: Extradición; Cooperación Internacional; Trámites.

\section{Abstract}

Objective: to describe the process of extradition of Colombians requested by International Courts of Justice, from the experience of the Foundation for the Defense of Colombians with orders of extradition (DECOPEX), in order to set a source of reference on extradition in Colombia in the last three decades. Methodology: a descriptive and documental study was conducted in two phases: first, the description of the study was carried out based on interviews to 650 prisoners from Pavilion 7 on Saturdays between 2007 and 2011. In the second phase, written material about legal and management aspects in the DECOPEX Foundation and in a literature review was compiled. Results: 1221 people were extradited between 2000 and 2011; the highest number of extraditions occurred in 2008: 207. The countries with the highest number of requests were United States, Spain and Peru. The main crimes are: drug trafficking (75\%); crimes related to drug trafficking (11\%); money laundering (10\%); homicides (2\%); and smuggling of migrants (1\%). Conclusions: for the last three decades, in Colombia the extradition is applied as a mechanism to facilitate judicial cooperation between countries. This is a process that lasts between 12 to 18 months and is regulated in the Political Constitution of Colombia.

Keywords: Extradition; International Cooperation; Procedures.

\section{Resumo}

Objetivo: descrever o processo da extradição de colombianos solicitados pelos Tribunais Internacionais de Justiça, a partir da experiência da Fundação para a Defesa dos colombianos pedidos em extradição (DECOPEX); isto, a fim de concretizar uma fonte de consulta sobre a extradição, nas últimas três décadas na Colômbia. Metodologia: estudo descritivo e documental, estudo que foi desenvolvido em duas fases: primeiro, 
a descrição do estudo foi realizada com entradas geradas da entrevista a 650 detentos do Pavilhão Sete da prisão de Segurança máxima de Combita; tais entrevistas foram obtidas nas visitas dos sábados entre 2007 e 2011. Na segunda fase, de caráter documentário, compilou-se material escrito sobre os aspectos legais e de gestão na fundação DECOPEX e numa revisão bibliográfica. Resultados: entre 2000 e 2011 foram extraditados 1221; 2008 foi o maior número de extradições: 207. Os países que solicitam com o maior número de petições foram os Estados Unidos, Espanha e Peru. Os principais delitos são: o tráfico de droga, 75\%; crimes relacionados com o tráfico de droga, com 11\%; lavagem de dinheiro 10\%; assassinato 2\% e 1\% contrabando migrante.

Conclusões: na Colômbia a extradição tem sido aplicada por três décadas, como um mecanismo para facilitar a cooperação judicial entre os países. É um processo que dura entre 12 a 18 meses e é regulado pela Constituição da Colômbia.

Palavras-chave: Extradição; Cooperação Internacional; Procedimentos. 


\section{Introducción}

En Colombia, destaca la experiencia de la Organización No Gubernamental Fundación por la Defensa de los Colombianos Pedidos en Extradición (DECOPEX); su tarea es el apoyo a los procesos de cientos de colombianos solicitados en extradición a los que representó ante organismos gubernamentales para velar por sus derechos fundamentales.

Esta Organización No Gubernamental fue un espacio en el que convergieron los familiares de las personas detenidas con solicitud de extradición y que se encontraban recluidos en el Pabellón 7 de la Penitenciaría de Máxima seguridad de Cómbita ${ }^{1}$. Los propósitos primordiales de DECOPEX estuvieron enfocados en cuatro áreas estratégicas: la defensa de los derechos fundamentales de los reclusos y sus familias; el desarrollo de una estrategia jurídica en el ámbito nacional e internacional; la realización de lobby ante órganos gubernamentales, con el fin de reglamentar el procedimiento jurídico de la extradición y la función social ante la problemática de algunas personas que se encontraban detenidas injustamente.

La pertinencia de la presente investigación radica en que la extradición como figura jurídica de cooperación internacional se ha usado desde la época antigua hasta nuestros días, con el fin de combatir el delito transnacional; Colombia ha sido uno de los Estados pioneros en el estudio y aplicación de esta figura en el sistema internacional. Sin embargo, hoy, muchos colombianos aún desconocen, incluso, en el ámbito académico, cómo se lleva a cabo este procedimiento. Por ello, este artículo puede servir como fuente de consulta sobre el asunto en las últimas tres décadas.

Con el fin de cumplir describir el proceso legal de extradición, el principal propósito de este estudio, primero, se ofrece una visión general de la Extradición como Instrumento de cooperación jurídica transnacional. Para ello, se presenta un análisis conceptual sobre la extradición y sobre los tipos de extradición existentes. Luego, se expone la evolución histórica de la extradición en

\footnotetext{
1Cómbita es un municipio colombiano ubicado en la provincia del Centro en el departamento de Boyacá. Está situado sobre la Troncal Central del Norte a unos 8,5 km de la ciudad de Tunja, capital del departamento. En Cómbita se encuentra la cárcel, con capacidad para 1.600 reclusos de alta seguridad. La reclusión tiene siete pabellones para 204 internos, cada uno, con condenas de 10 a 30 años. Igualmente, cuenta con tres anillos de seguridad periférica (Policía, Ejército, Guardia penitenciaría) y en la parte interna cuatro anillos de cerramiento, uno de los cuales está compuesto por sensores, que al detectar a una persona en ese corredor, disparará la alarma y los reflectores.
} 
Colombia y se analizan los principios jurídicos que rigen el trámite de la extradición; a continuación se relacionan las fases mediante el cual se desarrolla el procedimiento en el territorio nacional y las instituciones que hacen parte de este proceso.

Al final, se da cuenta de la experiencia de la Fundación DECOPEX en defensa de los derechos fundamentales de las personas solicitadas extradición y recluidas en el Pabellón 7 de Máxima Seguridad de la Penitenciaría Cómbita. Desde DECOPEX se muestra, entre otras gestiones, el desarrollo de una estrategia jurídica en el ámbito nacional e que se dirigió a la interposición de las acciones jurídicas del habeas corpus y de la tutela, para que la Corte Suprema de Justicia de Colombia, estudiara jurídicamente cada uno de los casos y no le diera simplemente el trámite administrativo, que realiza hasta ahora para su aprobación; esta estrategia en el escenario internacional se basó en presentar una demanda ante la Corte Interamericana de Derechos Humanos.

\section{Antecedentes de la Extradición}

Según Colín (1993) el primer caso conocido de extradición, se remonta a la época antigua y es el ocurrido entre los Hititas y Egipto (1271 a. de C.) cuando se pactó un tratado de Paz entre Hatusie, "Gran jefe de Haittí-Ramses", y el Gran jefe de Egipto, en cuyas cláusulas quedo establecida la extradición, tanto de egipcios como de hititas (Colín, 1993).

En la edad media, la extradición era una forma muy segura de proteger los bienes tanto de los reyes como de los señores feudales, ya que existía un convenio firmado por ellos para procurar el resguardo de sus propiedades; por medio de este acuerdo se entregaban recíprocamente los enemigos personales, que tratando de huir, se refugiaban en territorio distinto del cual podría ser extraditado (Pentón, 2014).

En la edad moderna, con la Revolución Francesa se inició la discusión sobre los derechos del hombre, lo mismo que el Derecho Internacional y la extradición -con el contenido actual de su término-; ésta, respondía a la necesidad de deslindar la persecución política susceptible del derecho de asilo y la persecución por delincuencia común, propia de la extradición. Ya el convenio de 29 de septiembre de 1765 entre Carlos III de España y Luis XV de Francia, habla de la entrega del delincuente común por faltas graves, pero siempre sin excluir la entrega por razones políticas (Pentón, 2014). 
Sin embargo, es en el siglo XIX, con el antecedente de la Revolución Francesa y el moderno Estado de Derecho que, a partir del "Tratado de Paz de Amiens" (1803) entre Francia, España e Inglaterra, que se hace referencia a la extradición por delincuencia común y no se mencionan asuntos políticos. Y, a partir de la Ley emitida por Bélgica en octubre de 1833, se perfila la estructura formal y material de las leyes de extradición actuales, referidas exclusivamente a la entrega de delincuentes (Pentón, 2014).

Esto quiere decir que la extradición es una institución que tiene un vasto historial de usanza como mecanismo legal que facilita la colaboración judicial entre diversos países. De esta manera, los Estados han solicitado históricamente a individuos que se encuentran en otro territorio, con el objetivo de abrir o continuar un procedimiento penal contra éste.

\section{Análisis conceptual de la Extradición}

La palabra ex tradición proviene del griego ex, “afuera de” y del latín “traditionis”, que significa acción de entregar concretamente a una o más personas. (Colín, 1993). En ese mismo sentido, el Diccionario de la Real Academia Española lo define como "el procedimiento por el que las autoridades de un Estado hacen entrega de una persona a la de otro que la reclaman para que pueda ser enjuiciada penalmente este segundo o cumpla en él una pena ya impuesta” (RAE, 2016). Por su parte, el portal Word Reference define la extradición "como la entrega del refugiado o detenido en un país a las autoridades de otro que lo reclaman” (Word Reference, 2016).

En Colombia, en la década de los 80, juristas desarrollaron relevantes aportes conceptuales a la extradición como figura jurídica, debido al debate que suscitó la implementación de la extradición como lucha contra el narcotráfico. Molina (1980), señala que la institución de la extradición, surgió a la luz del Derecho Internacional Público y es un valioso instrumento de batalla que debe ser utilizado por los Estados, en su campaña en contra del crimen, siempre que en tal batalla se enfrentan, de manera aislada, a un enemigo de dimensiones internacionales.

Otro aporte importante es del penalista Alfonso Reyes Echandía, quien señaló que la extradición es un fenómeno que consiste básicamente en la solicitud, oferta o entrega de un procesado o condenado que un Estado hace a otro para continuar contra él un proceso iniciado o para hacer efectiva una sentencia de condena por hecho punible (Reyes, 1970). Igualmente, Pérez (1984) sostiene que "La extradición es el acto por medio del cual el Estado en cuyo territorio 
se ha refugiado el responsable de un delito cometido en el extranjero, entrega dicho sujeto al Estado donde ejecutó la infracción o al Estado a que pertenece el infractor" (p. 85).

Finalmente, en 2008, en Colombia, se otorga un enfoque al término relacionado con la cooperación internacional. En ese sentido, la Sentencia C-460 de 2008 de la Corte Constitucional, el Magistrado Ponente, Nilson Pinilla señala que "la extradición es entendida como un mecanismo de cooperación internacional que busca combatir el crimen y evitar la impunidad” (Sentencia C-460 de 2008).

\section{El trámite de la extradición en Colombia}

La extradición es un mecanismo de cooperación internacional que requiere la celebración de acuerdos bilaterales para su ejecución o la existencia de normas internas concernientes a dicho procedimiento. Colombia ha celebrado tratados bilaterales de extradición con doce Estados: Bélgica, Brasil, Chile, Costa Rica, Cuba, España, Francia, México, Nicaragua, Panamá, Perú, Reino Unido. De igual forma, ha suscrito dos tratados multilaterales: el Acuerdo sobre extradición celebrado en Caracas el 18 de julio de 1911 y el Convenio sobre extradición celebrado en Montevideo el 26 de diciembre de 1933 (Ministerio de Relaciones Exteriores de Colombia, 2014).

Así, desde el siglo XIX, Colombia fue uno de los primeros países en suscribir tratados internacionales de lucha contra el crimen, consciente de que el delito tenía que ser atacado más allá de las fronteras patrias y para evitar que nuestro país fuera refugio de delincuentes, según las motivaciones expuestas en esa época. En 1888, Colombia suscribió un tratado multilateral de extradición, en el que, por primera vez, se menciona el tráfico de sustancias controladas como delito causal de extradición y se fija la extradición por vía administrativa como mecanismo aplicable (El Tiempo, 2014).

En 1936 se introduce a la ley colombiana la extradición, para actualizar y adecuar lo que ya está en tratados internacionales. La extradición de nacionales se contempla en el Código Penal de ese año. Pero es en 1979 cuando el termino extradición fue conocido por la mayoría de los colombianos cuando el entonces embajador de Colombia en Washington, Virgilio Barco Vargas, suscribió el tratado de extradición con Estados Unidos. En este tratado quedó establecido que el Gobierno podrá extraditar previo concepto de la Sala Penal de la Corte Suprema de Justicia (El Tiempo, 2014). 
La extradición como herramienta de lucha contra el crimen organizado transnacional por parte del gobierno nacional empezó a ser utilizado en firme desde el año 1984 tras el asesinato del Ministro de Justicia Rodrigo Lara Bonilla. Desde esa época, empiezan las extradiciones en firme, especialmente hacia Estados Unidos, por delitos relacionados con el tráfico de drogas y el lavado de activos. Así, el 5 de enero de 1985 son extraditados los primeros cinco colombianos hacía Estados Unidos, entre ellos, el dirigente deportivo Hernán Botero Moreno (El Tiempo, 2014).

El presidente Virgilio Barco en 1989, a través de un decreto de Estado de sitio, fijó la extradición por vía administrativa; es decir, el Gobierno de manera autónoma asumirá y decidirá sobre los pedidos de extradición hacia Estados Unidos suspendiendo, mientras dure el Estado de excepción, las normas del Código Penal y de procedimiento sobre extradición. El Decreto que estableció la extradición por vía administrativa fue expedido el 18 de agosto, que coincidió con el asesinato de Luis Carlos Galán (El Tiempo, 2014).

En 1991 la Asamblea Constituyente, por primera vez en la historia jurídica y política de Colombia, elevó la extradición a rango constitucional y prohibió la entrega de nacionales. Las extradiciones en trámite son negadas y los presos recobraron la libertad. En 1997 se restablece la extradición de nacionales mediante ley aprobada en cuarto debate por la plenaria de la Cámara de Representantes, situación que sigue vigente (El Tiempo, 2014). En la actualidad, el procedimiento de la extradición está reglamentado en el Artículo 35 Constitución Política de Colombia (Art. 1 Acto Legislativo 01 de 1997) donde se señala que "La extradición se podrá solicitar conceder u ofrecer de acuerdo con los tratados públicos y, en su defecto, con la ley”.

\section{Clases de extradición reconocidas por el gobierno colombiano}

El Ministerio de Relaciones Exteriores de Colombia reconoce seis clases de extradición: Extradición activa, extradición pasiva, Re extradición, extradición en tránsito, extradición diferida, extradición simplificada, los cuales son explicados a continuación: 
Tabla No 1. Clases de extradición reconocidas por Colombia

\begin{tabular}{|c|c|}
\hline $\begin{array}{c}\text { Clase de } \\
\text { Extradición }\end{array}$ & Definición \\
\hline $\begin{array}{l}\text { 1. Extradición } \\
\text { Activa: }\end{array}$ & $\begin{array}{l}\text { Se denomina extradición activa al proceso fundamentalmente jurisdic- } \\
\text { cional a través del cual se sustancia la petición que un Estado a otro Es- } \\
\text { tado para que una persona le sea entregada privada de su libertad con } \\
\text { el objeto de ser sometida a proceso o para cumplir una pena privativa de } \\
\text { la libertad ya impuesta por autoridades jurisdiccionales del Estado so- } \\
\text { licitante (Ministerio de Relaciones Internacionales de Colombia, 2014) }\end{array}$ \\
\hline $\begin{array}{l}\text { 2. Extradición } \\
\text { Pasiva: }\end{array}$ & $\begin{array}{l}\text { La extradición pasiva se refiere a los eventos en que un Estado es reque- } \\
\text { rido, por encontrarse prófugo en su territorio el acusado o procesado } \\
\text { por un delito cometido en otro Estado o con efectos en éste, con miras } \\
\text { a su entrega (Ministerio de Relaciones Internacionales de Colombia, } \\
\text { 2014) }\end{array}$ \\
\hline 3. Re extradición & $\begin{array}{l}\text { Esta figura atiende a un mecanismo que tiene lugar cuando el Estado } \\
\text { que ha logrado obtener la extradición de una persona, recibe una nueva } \\
\text { solicitud por parte de un tercer Estado, para que ese mismo sujeto sea } \\
\text { enjuiciado u obligado a cumplir una pena en su territorio (Ministerio de } \\
\text { Relaciones Internacionales de Colombia, 2014) }\end{array}$ \\
\hline $\begin{array}{l}\text { 4. Extradición en } \\
\text { Tránsito }\end{array}$ & $\begin{array}{l}\text { La extradición en tránsito, implica una situación en la cual un Estado } \\
\text { permite el paso por su territorio, desde el Estado Requerido al Estado } \\
\text { Requirente, de una persona solicitada en extradición (Ministerio de Re- } \\
\text { laciones Internacionales de Colombia, 2014) }\end{array}$ \\
\hline $\begin{array}{l}\text { 5. Extradición } \\
\text { Diferida }\end{array}$ & $\begin{array}{l}\text { En virtud de lo previsto en el Artículo } 504 \text { del Código de Procedimiento } \\
\text { Penal, la extradición diferida se refiere a la facultad de la cual dispone el } \\
\text { Gobierno Nacional para diferir la entrega de la persona requerida has- } \\
\text { ta cuando sea juzgada y cumpla la pena o hasta que por preclusión de } \\
\text { la instrucción o sentencia absolutoria haya terminado el proceso, en el } \\
\text { evento en que el requerido hubiere delinquido en Colombia (Ministerio } \\
\text { de Relaciones Internacionales de Colombia, 2014) }\end{array}$ \\
\hline $\begin{array}{l}\text { 6. Extradición } \\
\text { Simplificada }\end{array}$ & $\begin{array}{l}\text { La extradición simplificada es un tipo de extradición creado mediante } \\
\text { la Ley } 1453 \text { de } 2011 \text { cuyo artículo } 70, \text { modificatorio del artículo } 500 \\
\text { de la Ley } 906 \text { de } 2004 \text { dispuso lo siguiente: "La persona requerida en } \\
\text { extradición, con la coadyuvancia de su defensor y del Ministerio Público } \\
\text { podrá renunciar al procedimiento previsto en este artículo y solicitar a } \\
\text { la Sala de Casación Penal de la Corte Suprema de Justicia de plano el } \\
\text { correspondiente concepto, a lo cual procederá dentro de los veinte (20) } \\
\text { días siguientes si se cumplen los presupuestos para hacerlo" (Ministerio } \\
\text { de Relaciones Internacionales, 2014) }\end{array}$ \\
\hline
\end{tabular}

Fuente: Ministerio de Relaciones Internacionales de Colombia (2014). 
Estas clases de extradición deben estar enmarcados en unos principios de Derecho Internacional que se detallan enseguida:

\section{Procedimientos en el trámite de la extradición en Colombia}

De acuerdo con la Dirección de Asuntos Jurídicos Internacionales del Ministerio de Relaciones Internacionales, el trámite de extradición en Colombia se desarrolla con las seis fases siguientes:

Tabla No 1. Clases de extradición reconocidas por Colombia

\begin{tabular}{|c|l|}
\hline Fase & \multicolumn{1}{|c|}{ Descripción del Procedimiento } \\
\hline Fase I & Mediante nota verbal, \\
\hline Fase II & $\begin{array}{l}\text { La Cancillería recibe del Ministerio de Justicia y del Derecho la solici- } \\
\text { tud de extradición de la persona requerida. El requerimiento respectivo } \\
\text { es efectuado por la autoridad judicial competente, a saber, un juez o un } \\
\text { fiscal. }\end{array}$ \\
\hline Fase III & $\begin{array}{l}\text { La autoridad judicial colombiana presenta la solicitud de extradición del } \\
\text { procesado o condenado ante el Ministerio de Justicia y del Derecho. } \\
\text { El Ministerio de Justicia y del Derecho examina la documentación pre- } \\
\text { sentada y, de cumplir con los requisitos legales exigidos, la envía al Mi- } \\
\text { nisterio de Relaciones Exteriores, que la cursará a la Representación } \\
\text { Diplomática respectiva. }\end{array}$ \\
\hline Fase IV & $\begin{array}{l}\text { La Representación Diplomática presenta la documentación al Ministe- } \\
\text { rio de Relaciones Exteriores del Estado requerido. }\end{array}$ \\
\hline Fase VI & $\begin{array}{l}\text { Si el idioma del Estado Requerido no es el castellano, la Cancillería so- } \\
\text { licitará, la traducción de la documentación al idioma del Estado Reque- } \\
\text { rido. }\end{array}$ \\
\hline Fase V & $\begin{array}{l}\text { La Dirección de Asuntos Jurídicos Internacionales de la Cancillería, me- } \\
\text { diante memorando dirigido a la respectiva Embajada de Colombia en el } \\
\text { exterior, presentará la documentación que soporta la solicitud formal } \\
\text { de extradición o detención preventiva con fines de extradición, ante el } \\
\text { Ministerio de Relaciones Exteriores del Estado Requerido }\end{array}$ \\
\hline $\begin{array}{l}\text { La Dirección de Asuntos Jurídicos Internacionales del MRE remite las } \\
\text { comunicaciones que se surtan entre la respectiva Embajada de Colom- } \\
\text { bia y el Estado requerido, a las autoridades nacionales competentes, a } \\
\text { través del Ministerio de Justicia y del Derecho. }\end{array}$ \\
\hline
\end{tabular}

Fuente: Dirección de Asuntos Jurídicos Internacionales

del Ministerio de Relaciones Internacionales (2014). 


\section{Autoridades que participan en el trámite de extradición en Colombia}

Son cinco autoridades colombianas sobre las que recae el procedimiento de extradición en Colombia: la Fiscalía General de la Nación, el Ministerio de Justicia y del Derecho, el Ministerio de Relaciones Exteriores, la Sala de Casación Penal de la Corte Suprema de Justicia y la Procuraduría General de la Nación, cuyas funciones se describen en la siguiente tabla:

Tabla No 3. Funciones de las autoridades en el trámite de extradición en Colombia

\begin{tabular}{|c|c|}
\hline Entidad & Función \\
\hline $\begin{array}{l}\text { 1. Fiscalía Gene- } \\
\text { ral de la Nación }\end{array}$ & $\begin{array}{l}\text { Se encarga de ordenar la captura, cuando sea precedente, de las perso- } \\
\text { nas solicitadas en extradición por el Estado requirente, aunado a esto } \\
\text { se suma la labor de poner a disposición de las autoridades del Estado } \\
\text { extranjero a esa persona, después de haberse surtido el trámite perti- } \\
\text { nente. }\end{array}$ \\
\hline $\begin{array}{l}\text { 2, Ministerio } \\
\text { de Justicia y del } \\
\text { Derecho }\end{array}$ & $\begin{array}{l}\text { Desempeña la labor de determinar, mediante acto administrativo s } \\
\text { ofrece o concede la extradición de una persona requerida por un Esta- } \\
\text { do extranjero. Su función implica un grado de interacción constante con } \\
\text { el Ministerio de Relaciones Exteriores y la Corte Suprema de Justicia }\end{array}$ \\
\hline $\begin{array}{l}\text { 3. Ministerio } \\
\text { de Relaciones } \\
\text { Exteriores }\end{array}$ & $\begin{array}{l}\text { Durante el trámite de formalización del pedido de extradición, correspon- } \\
\text { derá al Ministerio de Relaciones Exteriores adelantar la función de lega- } \\
\text { lización de la documentación cursada por parte del Estado Requirente. }\end{array}$ \\
\hline $\begin{array}{l}\text { 4. Corte Suprema } \\
\text { de Justicia - Sala } \\
\text { de Casación } \\
\text { Penal }\end{array}$ & $\begin{array}{l}\text { La competencia de la Corte Suprema de Justicia comprende la revisión } \\
\text { judicial que se realiza en Colombia del trámite de extradición donde se } \\
\text { verifica que el procedimiento no viole los principios de Extradición en } \\
\text { Colombia }\end{array}$ \\
\hline $\begin{array}{l}\text { 5. Ministerio } \\
\text { Público }\end{array}$ & $\begin{array}{l}\text { Actúa como garante de los derechos humanos y de los derechos funda- } \\
\text { mentales de los solicitados en extradición. }\end{array}$ \\
\hline Fase VI & $\begin{array}{l}\text { La Dirección de Asuntos Jurídicos Internacionales del MRE remite las } \\
\text { comunicaciones que se surtan entre la respectiva Embajada de Colom } \\
\text { bia y el Estado requerido, a las autoridades nacionales competentes, a } \\
\text { través del Ministerio de Justicia y del Derecho. }\end{array}$ \\
\hline
\end{tabular}

Fuente: Fundación DECOPEX (2010).

En síntesis, en el mecanismo de cooperación internacional, consagrado en el Artículo 35 Constitución Política de Colombia, el procedimiento más común es la extradición activa; se trata de un proceso jurisdiccional a través del cual se revisa la petición que un Estado a otro Estado para que una persona le sea entregada privada de su libertad, con el objeto de ser sometida a proceso 
o para cumplir una pena privativa de la libertad ya impuesta por autoridades jurisdiccionales del Estado solicitante.

\section{Metodología}

El camino metodológico para esta investigación fue de carácter descriptivo y documental y estuvo dividida en dos fases. La primera, de tipo descriptivo tomó como referencia la experiencia profesional del autor en la dirección de la Fundación DECOPEX. La población objeto de estudio fueron los 650 internos del Pabellón Siete de la Penitenciaria de Alta Seguridad de Cómbita que estuvieron recluidos entre los años 2007 y 2011. Los datos fueron tomados de las estadísticas generadas en la Dirección de la Fundación DECOPEX donde se tenía acceso a toda la información personal, familiar y jurídica de las personas solicitadas en extradición.

A los 650 internos extraditables, se les aplicó entrevista, mediante visitas todos los sábados entre 2007 y 2011; en estas entrevistas estuvieron presentes familiares y abogados de los internos. La segunda fase de esta investigación fue de carácter documental; se enfocó en la recopilación del material escrito sobre los aspectos legales y de gestión en la dirección de la Fundación DECOPEX y en una revisión bibliográfica sobre la temática.

\section{Resultados}

Primero, se presentaran las características de la población penitenciaria en trámite para su señalando sus regiones de origen, sus profesiones y los delitos por los cuales eran solicitados en extradición. Adicionalmente, se presentan las áreas estratégicas de gestión de la Fundación DECOPEX donde se buscó proteger el respeto de los derechos fundamentales de las personas solicitadas extradición recluidas en el Pabellón Siete de Máxima Seguridad de la Penitenciaria Combita.

\section{Principales regiones de origen (Pabellón 7, Penitenciaría de Cómbita)}

Se determinaron los orígenes de los reclusos solicitados en extradición durante el periodo 2007 -2011. Los grupos más sobresalientes provenían de la Región del Pacífico colombiano especialmente de Tumaco y Buenaventura con casi el 35\% de la población penitenciaria a la espera de su extradición, seguido 
de nacidos la Costa Atlántica y de San Andrés y Providencia con un 20\%; provenientes del Departamento de Antioquia, un 15\%, del Valle del Cauca un 10\% y un 20\% proveniente del resto del país (DECOPEX, 2011).

Las estadísticas presentadas en el gráfico No. 1, señalan cómo los departamentos que realizaron un mayor aporte a la comunidad de extraditables entre los años 2007 y 2011, fueron los ubicados en la Costa Atlántica y Pacífica con un $55 \%$, la mayoría de ellos afrodescendientes y con actividades relacionadas al transporte marítimo. Estas regiones costeras han sido tradicionalmente utilizadas por las organizaciones de narcotráfico para realizar sus envíos vía marítima especialmente a Estados Unidos y Centro América.

En Antioquia y el Valle del Cauca, con un $35 \%$ de participación en la comunidad penitenciaria del Pabellón Siete de Máxima Seguridad de Cómbita, surgieron los denominados Carteles de Medellín y Cali; además, en estos departamentos, en la década de los años noventa y principios del siglo XX, se desarrollaron actividades relacionadas al tráfico de estupefacientes, que en algunos casos siguen vigentes.

\section{Gráfico No 1. Principales regiones de origen al Pabellón 7 Penitenciaría de Cómbita}

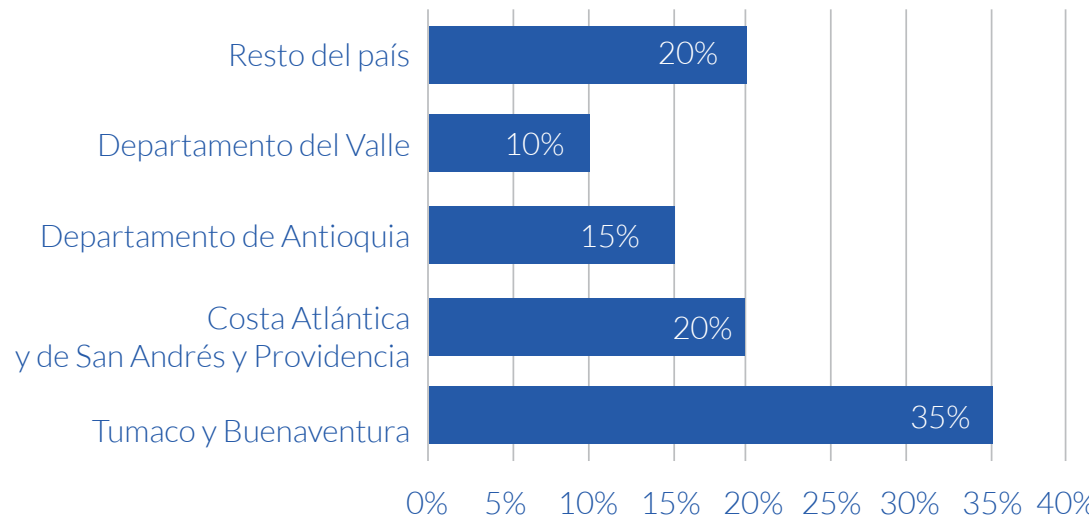

Fuente DECOPEX(2011)

\section{Principales profesiones de colombianos solicitados en extradición, del Pabellón 7 Penitenciaría de Cómbita}

En cuanto a las profesiones de los reclusos del Pabellón Siete de la Penitenciaria de Máxima Seguridad de Combita el grafico No 2 señala que la 
ocupación más predominante era la de comerciante independiente con un 45\%, seguido por empresario con un $20 \%$ y en una menor proporción se encontraban Oficiales y Sub-oficiales de las fuerzas militares y de Policía, miembros de grupos insurgentes de la FARC y el ELN; también figuraban tapiceros, choferes, recepcionistas, agricultores, jubilados de instituciones bancarias, vendedores ambulantes de plátano; sobre este grupo minoritario se enfocó el trabajo de la Fundación DECOPEX.

\section{Gráfico No 1. Principales regiones de origen al Pabellón 7 Penitenciaría de Cómbita}

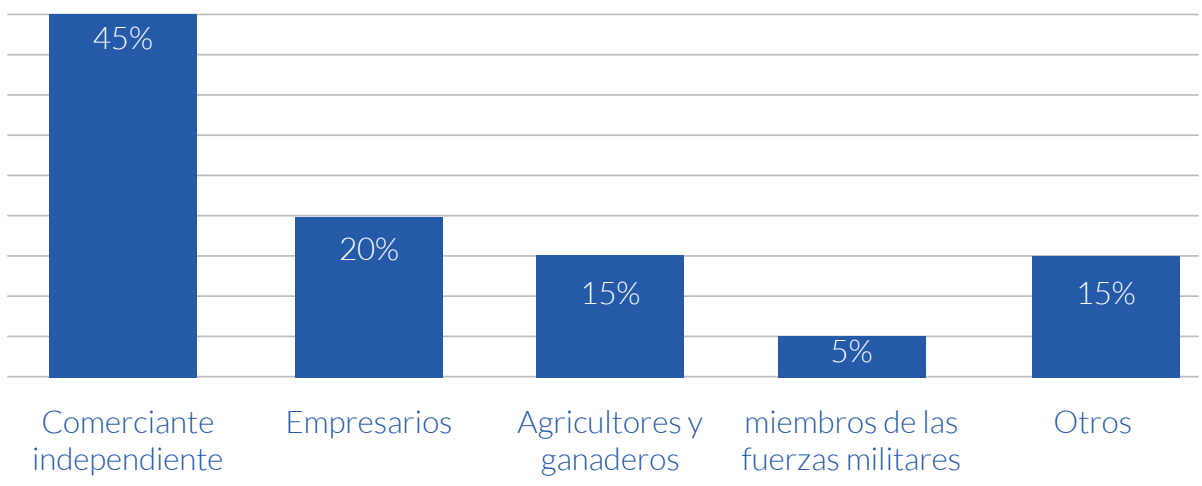

Fuente DECOPEX (2011)

En este factor de análisis era preocupante el alto número de miembros de las fuerzas armadas que hacían parte de los integrantes con solicitudes de extradición donde se destacaban oficiales de alto rango como coroneles, capitanes de la Policía Nacional, del Ejército Nacional y de la Armada Nacional de Colombia, acusados por el gobierno de Estados Unidos por colaborar con grupos delictivos en actividades de narcotráfico.

\section{Principales delitos por solicitudes de extradición 2007-2011}

En cuanto a los delitos por solicitudes de extradición entre 2000-2011, estadísticas proporcionadas por el Ministerio de Justicia de Colombia (2012) y que se presentan en el gráfico No. 3, señalan que en este periodo fueron extraditados 1221 colombianos; se encontró que el año 2008 fue en el que más se produjeron extradiciones, con 207. Los países requirentes con mayor número de solicitudes fueron Estados Unidos, España y Perú. En cuanto a principales delitos se destaca el narcotráfico con un $75 \%$ de los colombianos extraditados 
seguido por delitos relacionados al narcotráfico con $11 \%$, lavado de activos con $10 \%$, homicidio $2 \%$ y tráfico de migrantes $1 \%$. (Ministerio de Justicia de Colombia, 2012).

Gráfico No 3. Principales delitos por solicitudes de extradición de los reclusos del Pabellón 7 de la Penitenciaría de Cómbita 2007-2011.

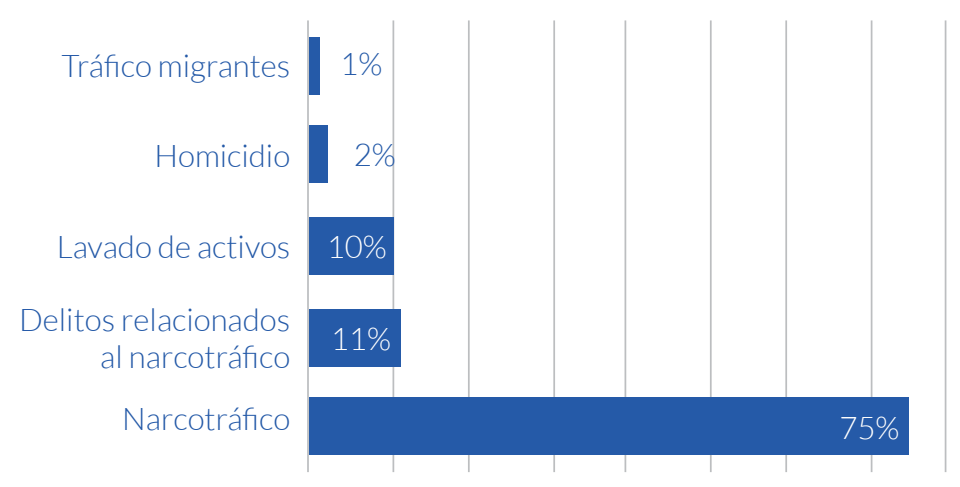

0\% $\quad 10 \% \quad 20 \% \quad 30 \% \quad 40 \% \quad 50 \% \quad 60 \% \quad 70 \% \quad 80 \%$

Fuente: Ministerio de Justicia de Colombia (2012)

\section{Resultados de la Gestión de la Fundación DECOPEX}

La Fundación DECOPEX fue una Organización No Gubernamental que funcionó entre los años 2007 y 2010 con sede en Bogotá, la cual propendía por la defensa de los derechos de los colombianos solicitados en extradición por Cortes internacionales. Estaba conformada, principalmente, por familiares de personas que se encontraban recluidas en el Pabellón Siete de la Penitenciaria de Alta Seguridad ubicada en el Municipio de Cómbita, Boyacá. Esta ONG fue presidida por el autor del presente artículo en calidad de Gerente y de Representante Legal.

Los propósitos primordiales de la Fundación DECOPEX estuvieron enfocados en cuatro áreas estratégicas de gestión. En la primera, se propuso velar por el respeto de los derechos fundamentales de los reclusos y sus familias; en la segunda, el desarrollo de una estrategia jurídica en el ámbito nacional e internacional; la tercera, la realización de lobby ante órganos gubernamentales con el fin de reglamentar el procedimiento jurídico de la extradición y, la cuarta área de gestión, estuvo enfocada en la función social ante la problemática de 
algunas personas que se encontraban detenidas injustamente. Estas áreas de gestión de la ONG DECOPEX se presentan a continuación.

\section{Debate por el respeto de los derechos fundamentales de las personas solicitadas en extradición y de sus familias}

Hasta el año 2012 las personas solicitadas en extradición, que se encontraban a la espera de su envío hacia los Estados Requirentes, eran recluidas en el Pabellón de Máxima Seguridad de la Penitenciaría ubicada en el Municipio de Cómbita (Boyacá). Esta cárcel está a 20 minutos de la ciudad de Tunja, capital del departamento de Boyacá; es considerada por expertos en seguridad como la más segura de Latinoamérica por su ubicación geográfica y por la avanzada tecnología con la que fue dotada.

A esta penitenciaría eran enviados los reclusos solicitados en extradición a la espera de la autorización por la Corte Suprema de Justicia. Esta prisión, cuenta con capacidad para 1.600 reclusos; hizo parte de un convenio entre el gobierno colombiano y el estadounidense, que buscó cambiar el sistema penitenciario en el país, con recursos provenientes del Plan Colombia. Esta penitenciaría es conocida por la rigurosidad de su sistema de seguridad, al contar con tres anillos de seguridad periférica (Policía, Ejército, Guardia penitenciaria) y en la parte interna cuatro anillos de cerramiento, uno de los cuales está compuesto por sensores, que al detectar a una persona en ese corredor, disparará la alarma y los reflectores (INPEC, 2016).

La Fundación DECOPEX originó un debate, con las entidades gubernamentales, en del Consejo Superior de Criminalística, encaminado a mejorar las condiciones de reclusión de los reos en el Patio Siete de la Cárcel de Alta Seguridad de Cómbita, debido a problemas de hacinamiento, condiciones de insalubridad, violaciones al debido proceso y el régimen de horarios de visita. De igual forma, a los familiares que realizaban las visitas le fueron vulnerados derechos sus derechos fundamentales por el entorno agreste de las visitas: hacían filas de hasta 6 horas en la madrugada a temperaturas de bajo cero grados centígrados, además, recibiendo, en ocasiones, abusos por el personal del Instituto Nacional Penitenciario de Colombia (INPEC).

Los resultados de este debate se vieron expresados en una visita realizada a la Penitenciaría de Cómbita por el Viceministro de Justicia de la época, Guillermo Francisco Reyes González, el Defensor del Pueblo de Boyacá Gustavo Adolfo Tobo, el Director General del INPEC Eduardo Morales Beltrán y enviados 
de la Procuraduría General de la Nación, donde se verificaron las condiciones precarias de reclusión dentro de este centro penitenciario.

Como consecuencia, a partir del año 2012 el gobierno nacional tomó la decisión de reubicar a los denominados extraditables en el piso 9 del pabellón de la cárcel La Picota, ubicada en Bogotá, para hacer más fácil las visitas de los familiares y de los abogados a las personas solicitadas en extradición.

\section{Estrategia juridica para interponer recursos judiciales colectivos}

La estrategia desarrollada en el plano jurídico de la Fundación DECOPEX se desarrolló tanto en el plano nacional como internacional interponiendo recursos jurídicos en las cortes nacionales y en la Corte Interamericana de Derechos Humanos.

La estrategia en el escenario internacional se basó en presentar una demanda ante la Corte Interamericana de Derechos Humanos en Octubre 26 del 2007, utilizando el argumento de que en el proceso de extradición de colombianos al exterior se presentaba una violación masiva al derecho fundamental del Non bis in ídem al ser juzgados los colombianos solicitados en extradición dos veces por el mismo hecho, una en Colombia y la otra en el país que realiza el requerimiento.

\section{Realización de lobby ante el gobierno nacional y el Congreso de la República}

El procedimiento jurídico de la extradición en Colombia se limita al estudio, en la Corte Suprema de Justicia, del cumplimiento de unos requisitos básicos y su posterior aprobación. Este procedimiento es considerado por algunos juristas como un simple "procedimiento notarial”.

Para contribuir a reglamentar el procedimiento jurídico de la extradición la Fundación DECOPEX realizó actividades de Lobby ante algunos Senadores y Representantes a la Cámara de Colombia. Este lobby, con el fin de solicitar la convocatoria del Consejo Superior de Criminalística para que se estudiara y reglamentara el procedimiento de la extradición y la cooperación internacional por el gobierno colombiano. La gestión no tuvo mucho éxito, debido a que la extradición en Colombia todavía es tema vedado para la opinión pública y, por ende, no trae consigo dividendos políticos, sino que por el contrario se guarda desconfianza con este tema por la creencia de que todos los solicitados en extradición son capos del narcotráfico. 


\section{Función social ante las injusticias con la Implementación en trámite}

Existe la creencia popular de que todas las personas solicitadas en extradición son personas adineradas por estar involucradas en el narcotráfico o el lavado de activos. Sin embargo, la realidad de algunas personas detenidas en el Pabellón Siete de la Cárcel de Cómbita distaba mucho de tal percepción. En este pabellón, había personas con profesiones disímiles como tapiceros, agricultores, choferes, jubilados de entidades bancarias y celadores, que en ocasiones no tenían los recursos económicos para los desplazamientos de sus familiares y el pago de honorarios profesionales de abogados. En ocasiones y gracias a actividades organizadas por los familiares, se alcanzó a reunir dinero para ayudar a estas personas.

Otro aspecto en el que se hizo una labor productiva fue en el campo de la denuncia. Una de las principales críticas de la Fundación DECOPEX realizadas al procedimiento de extradición de colombianos al exterior, estaba relacionada a los continuos errores de las autoridades colombianas y las del país solicitante, en la identificación de los detenidos.

Durante la gestión de la Fundación DECOPEX se presentaron casos muy sonados en los medios de comunicación sobre personas inocentes que estaban recluidas en espera de su ex tradición y que con el tiempo se demostró su inocencia; por ejemplo, al confundir sus identidades o al darle cierta interpretación al sentido de las conversaciones telefónicas.

El caso más representativo fue el de Gabriel Consuegra, el vendedor de plátanos extraditado a los Estados Unidos por error y que fue bautizado por las autoridades con el alias de "El Platanero". Consuegra fue acusado por la justicia norteamericana de ser el titular de varias cuentas bancarias, en diversos países de la cuenca del Caribe, que eran utilizadas para lavar activos procedentes del negocio del narcotráfico. Según el proceso, su hijo, en ese entonces de 23 años y estudiante de enfermería, había participado en el lavado de dólares en Colombia.

El señor Consuegra y su hijo fueron repatriados a Colombia luego de pagar una pena de 3 años sin encontrar cargos en su contra y las únicas pruebas presentadas por el gobierno de Estados Unidos fueron unas grabaciones telefónicas donde los implicados hablaban de "verdes" al referirse a plátanos verdes; sin embargo, la interpretación de las autoridades policiales de Colombia y Estados Unidos es que se referían a dólares; así los acusaron de pertenecer a una estructura de lavado de dinero. 
Otro caso fue el del señor Juan Vicente Gómez Castrillón, quien fue solicitado por el Tribunal del Distrito de los Estados Unidos para el Distrito Sur de Nueva York y en su descripción física era presentado como "un hombre caucásico", pero el señor Gómez es de raza negra. Además de este error, más otros relacionadas con su nombre y su edad, pues el hombre solicitado tenía 48 años mientras que Castrillón estaba próximo a cumplir los 70 años, son pruebas de la fragilidad del sistema de extradición en Colombia.

\section{Conclusiones}

La extradición es una institución que tiene un vasto historial de usanza como mecanismo legal que facilita la colaboración judicial entre diversos países. De esta manera, los Estados han solicitado históricamente a individuos que se encuentran en otro territorio con el objetivo de abrir o continuar un procedimiento penal en contra de éste

En Colombia desde hace tres décadas, la figura de la extradición ha enmarcado uno de los procesos más importantes en cuanto a la lucha contra diversos delitos como el narcotráfico y el lavado de activos. En la actualidad, el procedimiento de la extradición está reglamentado en el Artículo 35 Constitución Política de Colombia (Art. 1 Acto Legislativo 01 de 1997) donde se señala que "La extradición se podrá solicitar conceder u ofrecer de acuerdo con los tratados públicos y, en su defecto, con la ley.

El procedimiento de extradición de colombianos requeridos por cortes internacionales tarda entre 12 y 18 meses a la espera que se cumpla con el trámite en las instancias: Oficina de Asuntos Internacionales de la Fiscalía General de la Nación, la Corte Suprema de Justicia y el Ministerio de Justicia. Durante este tiempo de espera, estos colombianos son recluidos en Cárceles de Máxima Seguridad (Cómbita y la Picota) donde se ven enfrentados a la rigidez del sistema penitenciario caracterizado por el hacinamiento, alimentación inadecuada y la constante violación de derechos fundamentales por los miembros del INPEC a los internos y a los familiares que realizan semanalmente sus visitas. Es por ello que muchos colombianos solicitados en extradición prefieren agilizar el proceso para ser extraditados, pues en muchos países requirentes se goza de una mejor calidad de vida en las cárceles. 


\section{Referencias}

Barroso, C. G. (1982). Interpol y el procedimiento de extradición. Washington, Estados Unidos.

Calaza, S. y López, R. (2014). Mecanismos judiciales de cooperación internacional versus áreas de impunidad de la delincuencia. Caracas, Venezuela.

Calaza, S. y López, R. (2012). Cooperación judicial internacional extradición y euro orden. Caracas. Venezuela.

Comité Internacional de la Cruz Roja [CICR] (2014). Cooperación en el ámbito de la extradición y de la asistencia mutua judicial en materia penal internacional. Boletín CICR, 1(88).

Colín, G. (1993). Procedimiento para la extradición. México: Ed. Porrúa.

Dirección de Asuntos Jurídicos Internacionales Ministerio de Relaciones Internacionales (2014). Guía práctica sobre la extradición. Bogotá, Colombia: Ministerio de Relaciones Internacionales

European Commission- Directorate-General for Justice (2013). Estudio sobre cooperación jurídica, auxilio judicial internacional y extradición en material de tráfico de drogas y otros delitos relacionados, entre la UE y sus Estados miembro y los países de América Latina y el Caribe. Luxembourg: Publications Office of the European Union.

El Tiempo (10 de abril, 2014). La historia jurídica de la extradición. El Tiempo, 23. http://www.eltiempo.com/archivo/documento/MAM-597829

Guanumen, M. (2012). La narcotización de las relaciones Colombia-Estados Unidos. Estrategia y Seguridad, 7(2), 22 1-244.

Sanmartín, C. (2012). La extradición y la cooperación judicial internacional. Lima, Perú: Ed. Pontificia Universidad Católica del Perú.

Méndez, R. (2000). La firma de los tratados. Cuestiones Constitucionales, julio-diciembre, 
Ministerio de Relaciones Exteriores de Colombia (2014). Tratados bilaterales y regionales. Bogotá, Colombia.

Ministerio de Justicia de Colombia (2012). Evolución de la extradición principales países destino y delitos 2000 y 2011.

Molina, C. (1980). Análisis crítico de la Ley 27 de 1980: Tratado de extradición entre Colombia y Estados Unidos. Revista Facultad de Derecho y Ciencias Políticas. Universidad Pontificia Bolivariana.

Penton, A. (2012). Antecedentes históricos de la extradición.

Pérez, L. (1984). Derecho penal: partes general y especial. Bogotá, Colombia: Ed Norma.

Peña, J. R. (1974). La extradición. Revista Chilena de Derecho, 1(3/4), 375-380.

Ramírez, J. (2010). Informe de Gestión. Fundación DECOPEX. Bogotá, Colombia.

Reyes, A. (1970). Diccionario de Derecho Penal. Bogotá, Colombia: Universidad del Rosario

Corte Constitucional de Colombia (2008). Sentencia C-460 de 2008. Magistrado Ponente Dr. Nilson Pinilla Pinilla

Verduzco, G. R., y Verduzco, A. A. G. R. (2000). Extradición en derecho internacional aspectos y tendencias relevantes. México: Universidad Nacional Autónoma de México. 